\title{
Hemiplejia Infantil Aguda y Septicemia
}

\author{
Drs. Juan C. Casterán V.1, Mario Cerda $S_{-}^{1}$, Jorge Forster M. ${ }^{2}$, \\ Luis Sclstack P.2
}

\section{Sepsis and Acute Hemiplejia in Infancy}

\begin{abstract}
A ten month old child with Sepsis and acute Hemiplejia is presented. Anamnesis, evolution and posterior recovery are described. The principal features about this disease are commented.
\end{abstract}

La Hemiplejia Infantil Aguda en Pediatría es tambiér conocida como Hemiplejia Infantil Adquirida, Encefalitis de Marie Strumpel y Sindro. me de hemiconvulsión y Hemiplejis.

Esta definición excluye niños con antecedentes de Hemiplejia por causas perinatales.

La Hemiplejia Infantil no es una enfermedad sino más bien una respuesta inespecífica del S.N.C, de varias etiologías. Esta condición primaria o secundaria afecta los vasos cerebrales, pudiendo producirse isquemia o necrosis si las demandas de sangrc superan los aportes. La Hemiplejia es el principal signo clínico de este estado isquémico o necrótico, mientras que el modo de comienzo, curso clínico, pronóstico y el manejo dependen de la etiología. Por esta razón la Hemplejia puede ser sintomática o idiopática.

\section{Caso Clínico}

L.A.G.C., lactante de diez meses, de sexo masculino, quien seis dias antes del ingreso presenta fiebre, vómitos y deposiciones líquidas, apareciendo luego convulsiones tónico-clónicas generalizadas que motivaron su ingreso al Servicio de Pediatría del Hospital de Talca.

En dicho establecimiento se constata lactante afebril, levemente deshidratado, hipotónico. Se le indicó regimen o e hidratación parenteral, con lo que se recupera rápidamente.

A las pocas horas se describe: conciente, lícido, hidratado y sentado en la cuna. Al día siguiente amanece en coma superficial con franca disminución de la sensibilidad, hipotonía e hipo. rreflexia, presentando en el curso de ese dia inicialmente convulsiones de hemi-cuerpo izquierdo que posteriormente se generalizan. Por glicemia de $44 \mathrm{mg}, \%$, se indica carga glucosada de $8 \mathrm{mg} / \mathrm{kg} / \mathrm{min}$., previa administración de glucosa hipertónica iniciándose tratamiento preventivo de edema cerebral con manitol $1,5 \mathrm{~g} / \mathrm{kg} /$ dosis

\footnotetext{
1 Médico U.C. I. Pediatria Hospital Sótero del Río.

2 Médico Neurología Infantil Hospital Sótero del Río.
}

cada 6 horas y dexametasona $2 \mathrm{mg}$, cada 6 horas, planteándose el diagnóstico de S. Reye. A pesar del tratamiento persisten las convulsiones, constatándose nueva glicemia de $27.2 \mathrm{mg}$, por lo que se aumenta la carga de glucosa a 10 $\mathrm{mg} / \mathrm{kg} / \mathrm{min}$. Se indica vit., $K$ por acusar protombina de $13 \%$ y cimetidina como preventiva de hemorragia digestiva. En estas condiciones se decide su traslado al Hospital Josefina Martinez con diagnóstico de coma en estudio, iS. de Reye? , Hipoglicemia. Un hemograma revelaba leucocitosis de 18.400 , con Hto., de $32 \%$, motivo por lo que se indicó sangre. Las transaminasas fueron normales.

lngresó conciente, irritable, con equimosis en los sitios de punción, anisocoria y reflejo foto-motor negativo a izquierda, hipotonia e hiporreflexia generalizada más acentuada a izquierda. Se deja con carga glucosada de $6 \mathrm{mg} / \mathrm{kg} / \mathrm{min}$, restricción hídrica, manitol, 0,5 $\mathrm{g} / \mathrm{kg} /$ dosis e hidrocortisona $.50 \mathrm{mg} / \mathrm{kg} /$ dosis ev. Durante los próximos días continúa con compromiso variable de conciencia sin llegar al coma presentando repetidas crisis convulsivas de hemicuerpo izquierdo, que no compromete sensorio, instalándose en forma progresiva una hemiparesia faciobraquiocrural izquierda de predominio braquial. Un EEG., tres días después de iniciado el cuadro convulsivo reveló asimetría importante con signos de daño neuronal de predominio posterior derecho y elementos irritativos sobre áreas anteriores de este hemisferio. Una tomografía axial computarizada (TAC) efectuada nueve días después de iniciada la enfermedad, reveló "imagen sugerente de extenso reblandecimiento que compromete el hemisferio cerebral derecho en su totalidad, por probable oclusión de vaso mayor", sin embargo la arteriografía carotidea derecha, practicada veinte días después fue informada como normal. El EEG., de control (trece dias después del primero) conchuye dafío netro. nal sobre hemisferio derecho e importante actividad irritativa sobre ese hemisferio.

Los hemocultivos tomados al ingreso fueron positjvos a Klebsiella, sensible a Amikacina, anti- 
biótico con que se trató desde el ingreso. El cultivo de virus en LCR., fue negativo para herpes y también el cuitivo para enterovirus en deposiciones.

Durante toda su hospitalización presentó un cuadro convulsivo caracterizado por clonías de extremidades izquierdas que cedian espontáneamente o con la administración de dosis bajas de diazepam ev. Al comienzo se intentó yugular este cuadro convulsivo con fenobarbital $10 \mathrm{mg} / \mathrm{kg}$. Al no obtenerse respuesta se cambió por fenitoíta en dosis de hasta $10 \mathrm{mg} / \mathrm{kg}$. E1 nivel plasmático de fenitoína obtenido 15 días después de iniciada su administración estaba bajo el rango terapéutico.

Al alta, despues de 35 días de hospitalización se apreció: conciente, activo, afebril, franca hemiparesia izquierda con hipotonia e hipcrreflexia a ese nivel. Se indicó tratamiento kinćsico, estimulación sicomotora y tratamiento anticonvulsivante a permanencia con fenitoína $50 \mathrm{mg}$., cada 12 horas.

Un control neurológico efectuado nueve meses después de iniciada la enfermedad, informó que a pesar del tratamiento anticonvulsivante. persistían crisis focales motoras que afectaban a las extremidades izquierdas, de alta frecuencia y retraso de su desarrollo sicomotor.

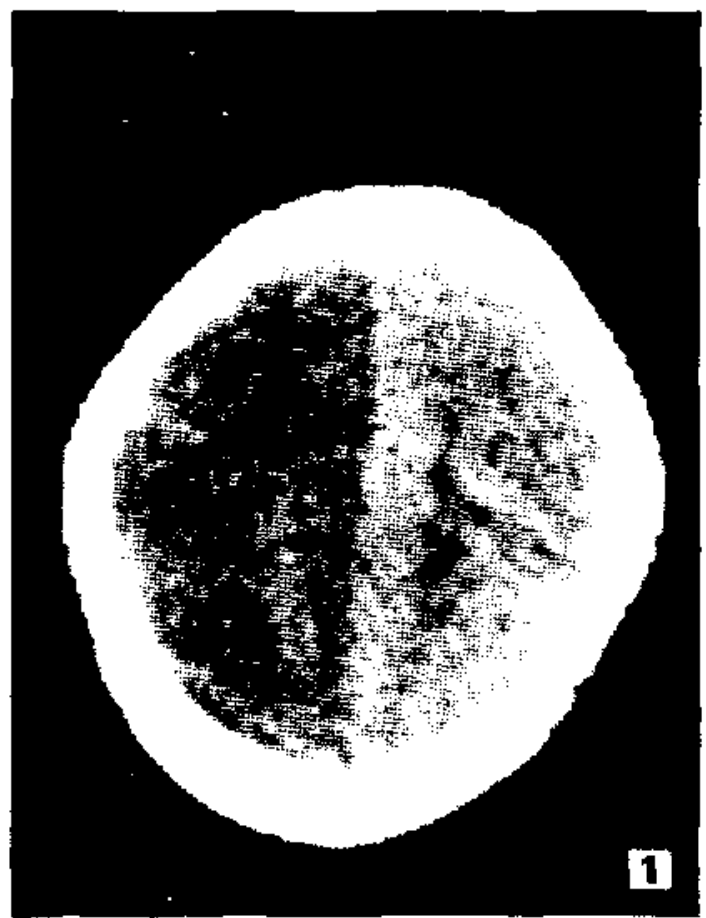

Figuras NOS 1 y 2. En las figuras \& y 2 se aprecian dos cortes de la TAC de cerebro efectuada al 90 día de evolución. Existie una franca asimetria de los hemisfirios con mayor densidad radiológica a defecha, sin

\section{COMENTARIO}

Entre los factores etiológicos de la Hemiplejia Infantil aguda sintomática, se mencionan las afecciones bacterianas generalizadas ${ }^{1.4}$ que pueden cursar con un sindrome de coagulación intravascular diseminada.

En este caso tenemos una septicemia a Klebsiella demostrada por hemocultivo de ingreso, en un lactante de diez meses con equimosis cutánea en sitios de veno punción y que hace un infarto de todo el hemisferio cerebral derecho. El depósito de plaquetas y lipidos sobre un endotelio vascular dañado por toxinas bacterianas puede obstruir un tronco arterial y provocar la isquemia consiguiente, muerte tisular y explicar así el infarto cerebral ${ }^{5}$.

La circulación cerebral en el niño, especialmente en el lactante, se caracteriza por una gran cantidad de anastómusis colaterales y los vasos son plegables y elásticss. El cerebro tiene la capacidad de mantener el flujo cerebral a un área isquémica y en muchos casos no aparecen signos de déficit neurológico si el territorio afectado es pequeño. Solamente la oclusión total de un tronco arterial importante tal como el sifón carotídeo permitirí entonces que la signología se

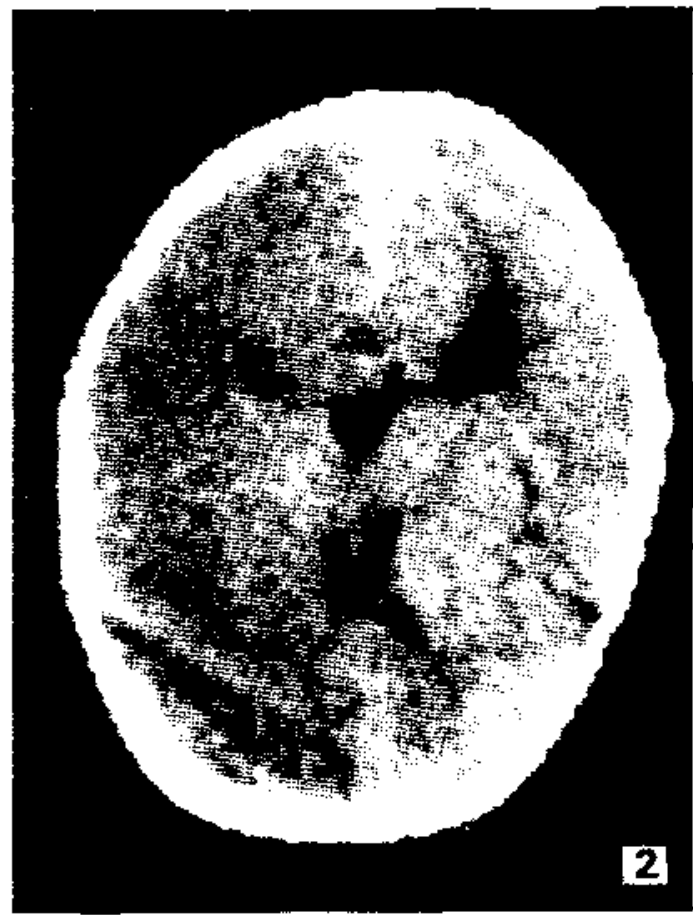

desplazamientos de la línea media con leve dilatación del cuerno anterior del ventrículo lateral derecho. Las imágenes son sugerentes de un extenso reblandecimicnto hemisférico derecho. 
haga evidente y esto podría plantearse en el caso de este lactante ${ }^{5}$. Por otrạ parte, en el níno, a diferencia del adulto la oclusión venosa es más frecuente y toma el aspecto de trombosis venosas cortićales, especialmente en cuadros sépticos ${ }^{3}$.

La oclusión vascular puede no demostrarse en un porcentaje de angiografias efectuadas precozmente en relación al comienzo de la signologia ${ }^{4}$ e incluso se plantea a yecs la posibilidad de espasmos vasculares transitorios como responsables de cuadros oclusivos ${ }^{1}$.

En este paciente, el hecho quc la arteriografia carotidea practicada 20 dras después de instalada la Hemiplejia fuera informada como normal, podría ser explicado por recanalización del tronco atterial ocluido ${ }^{7}$, si es que esta oclusión existió.

El comienzo del cuadro clínico de la Hemiple. jia Infantil con convulsiones hemigeneralizadas o focales efl cl hemicuerpo afectado, se describe como itabitual y es explicado por un fenómeno de hipoxia tisular. La alta frecuencia de estas convulsiones unido a los hallazgos de los EEG., que mostraban actividad irritativa y la edad del niñ̃o, debieran considerarse como índice de mal pro. nóstico $u$ de alto riesgo ${ }^{7}$ de secuelas neurológicas severas en este niño, ya en la etapa aguda de su enfermedad 4 .

E1 retraso sicomotor, la persistencia de crisis convulsivas y de la hemiparesia izquierda en el control neurológico alejado, parecen estar afir. mando este mal pronóstico.

En el niño, en muchas ocasiones, la espasticjdad despućs de una Hemiplejia se pesquisa tardiamente y a nivel distal de las extremidades (ej. dorsiflexión del pie) y sólo se aprecia la menor motilidad espontánea y la falta de fuerzas de las extremidades afectadas. Si no hay compromiso extenso del lóbulo pariecaI, no debe esperarse una hipotrofia muy importante y su apatición será tardia.

Dc 26 casos de Hemiplejia Aguda tratados en el Instituto de Neurocirugía de Santiago entre 1956 y 1975, 615 correspondian a menores de 15 años. La etiologia más frecuente fue la inffecciosa.

La relación por sexo es variable y depende de. la etjología.

Asi, los traumatismos ${ }^{8-9}$ la trombosis arterial ccrebral y la arteritis carotídea son más frecuentes en varones.

La enfermedad de Takayasu es más frecuente en las niñas 4 .

Los antecedentes perinatales $y$ la historia familiar no son importantes.

La edad de comienzo de la H.I.A., varía con la causa especifica ${ }^{7}$. Traumatismos e infecciones son más trecuentes en el perjodo preescolar. La enfermedad vascular oclusiva cerebral, asociada a cardiopatía congénita cjanótica se observa más frecuentemente en los primeros dos años de vida En general, la mayoría de los niños se hace sintomático antes de los seis años y de éstos al mayor numero antes de los tres años. Es rara la H.I.A. sobre los doce años.

El modo de comienzo de una H.l.A., ej variable $y$ depende de la enfermedad prima ia responsable de la hemiparesia ${ }^{7}$.

Hallazgos de laboratorio: En general, la mayoría de los exámenes habituales son normales excepto el LCR en accidentes vasculares e infecciones del SNC. El EEG revela anomalías elećtricas, descargas paroxisticas difusas o localizadas. La tomografía axial computarizada es, sin duda, la mejor técnica no invasiva y con un excelente rendimiento para el diagnóstico de una hemiplejia aguda. La angiografía tomada en cualquier estado de la ftemiplejia puede ser normal. Es de mucha utilidad ${ }^{7}$ en la enfermedad oclusiva de la caródita o de alguna de las arterias cerebrales secundaria a trombosis, embolía o arteritis.

Pronóstico: Está relacionado directamente con la condición responsable de la hemiplejia. El pronóstico en un niño depende de factores como la edad de comienzo, severidad de ta hemiparesia y la asociación con marifeștaciones neurológicas. Un $25 \%$ de los niños con H.I.A. ${ }^{7}$ fallecen durante la prinera fase de la enfermedad ya sea por status epilepticus o por la enfermedad causal. Aproximadamente un $75 \%$ de los sobrevivientes quedan con secuelas neurológicas consistentes en déficit motores sensitivos, convulsiones, retardo mental, así como desórdenes de conducta y aprendizaje.

Tres curacterísticas clinicas ayudan a formular un pronóstico.

La presencia de convulsiones al comínzo de la hemiplejia to hace mas ominoso ${ }^{3-4}$, ya que aumenta el riesgo de secuelas motor as y epilepsia residual.

La edad de comienzo: la mayoría de los niños menores de dos años tienen mal pronóstico ya que cualquiera sea la etiologia presentan convulsiones prolongadas, caracterîstica propia de un cerebro inmaduro ${ }^{3-4}$.

Los accidentes vasculares isquémicos tienen mejor pronóstico que los hemorrágicos en cuanto a porcentaje de sobrevida y secuelas ${ }^{2}$.

\section{RESUMEN}

Se presenta el caso de un lactante de 10 meses con Septicemia y Hemiplejia Infantil Aguda. Se describe anamnesis, evolución y seguimiento, comentándose las principales características de esta enfermedad. 


\section{REFERENCIAS}

1 Blewnow G. Cronguist. $S$, Hindfelt, B., and Nilsson $O$.: On cerebral infarction in childhood and adoles. cense. Acta. Pediatr. Scand. 67: 469, 1978.

2 Schoenberg B.S. Mellinger J.F and Schoenberg D.G.: Cerebro-vascular disease in infants and children. A study of incidence, clinical features, and survival. Neurology (NY) 28: 736, 1978.

3 Humphreys, R.P. Hendrick E.B. and Hoffman H.J.: Cerebro vascular disease in clildren. Can. Med. Assoc. J. 107: 774, 1972.

4 Solomon G.E. Hilal S.K. Gold A.P. ond Carter S.: Natural History of acute Hemiplejia of Childhood. Brain 93: 107, 1970.

5 Swaiman K. F. and Wright F.S.: Text - Book "The practice of pediatric Neurology. The C.V. Mosby Company 1982, pag. 765 a 770 . Vascular diseases of the brain and psinal cord.

6 Chiofalo, N. Madsen, J., Fuentes, A., Basaturi L. And. Castro, M.: Oclussive arterial. Disease of the Child and young adult. Child's Brain 4: 1-14, $197 \mathrm{~b}$.

7 Gold. A.P., Carter S.: Acute Hemiplejia of Infancy and Child hood. Pediatt. Clin. North. Am. 23: 413 -- 433, 1976.

8 Woodhurst, WB., Roberison, W.D. Thompson G.B.: Carotid injury due to intra orad trauma: Case report and review of the literature. Neurosurgery $6: 559$, 1980.

9 Brousse C., Casterdin J.C., Femández M.E.: Trombosis carotídea por trauma intraoral. Rev. Chil. Pediat. 53: 149,1982 . 